\title{
Performance Analysis of Inclined Heat Pipe using Alumina Nanofluid
}

\author{
Ezra Vijay Anand and Amol Andhare
}

\author{
Department of Mechanical Engineering, Shri Ramdeobaba College of Engineering and Management,
} Gittikhadan - 440013, Nagpur, Maharashtra, India; ezraanand@gmail.com, andhaream@rknec.edu

\begin{abstract}
Heat pipes are the effective heat transfer devices capable of transmitting high heat fluxes rejected by modern day equipment. In the present study, an experimental investigation has been carried out to evaluate the enhancement in the thermal performance of mesh and sintered wick heat pipes charged with $\mathrm{Al}_{2} \mathrm{O}_{3} /$ DI (Deionized water) nanofluid. Geometrical specifications of 12.7, 600 and $1 \mathrm{~mm}$ are selected as the outer diameter, length and wick thickness respectively and are kept constant for both sintered and mesh wick heat pipes. This work discusses about the effect of heat pipe inclination, type of working fluid and heat input on the thermal resistance and thermal efficiency. The results showed that the maximum reduction in thermal resistance is obtained for mesh wick heat pipe at $45^{\circ}$ tilt angle and $60^{\circ}$ for sintered wick heat pipe with $\mathrm{Al}_{2} \mathrm{O}_{3} / \mathrm{DI}$ water nanofluid concentration at $1.0 \mathrm{wt}$. \% for both the cases. Further an enhancement in the thermal efficiency of $37.55 \%$ and $41.38 \%$ for mesh wick and sintered wick heat pipes respectively is observed for the same concentration. Experimental results show that the inclination angle has a strong effect on the thermal performance of heat pipes using both water and the nanofluid.
\end{abstract}

Keywords: Inclination Angle, Mesh Wick Heat Pipe, Nanofluid, Sintered Wick Heat Pipe

\section{Introduction}

Thermal management system in modern day applications is currently a very important issue. The heat pipe is a two phase highly effective heat transfer device over other conventional methods. It can transport large quantities of heat through a small cross-sectional area over a considerable distance with no external power input to the system.

Experimental ${ }^{1}$ investigation was carried out to study the thermal performance of a sintered-wick heat pipe with water as a working fluid at various inclinations with gravity assisted tilt. The study discusses about the effect of heat pipe inclination, type of working fluid and heat input on the thermal efficiency and thermal resistance. It was observed that the temperature decreases with increase in length along the heat pipe at different heat fluxes. From the experimental results it is observed that, as the evaporator section is moving towards the ground the heat transporting ability of heat pipe is increasing up to $60^{\circ}$ and from then onwards it goes on decreasing.

Investigated ${ }^{2}$ performance of heat pipe with Al2O3-water nanofluid using a cationic chitosan dispersant. The optimum filling ratio was at $20-40 \%$ range. Tilt angle for maximum performance was $40-70^{\circ}$.

For lower concentration, higher thermal performance was obtained at lower filling ratio. For higher concentration, higher thermal performance was obtained at high filling ratio. At higher concentration of nanoparticle, a drop in thermal efficiency occurs due to drop in convective heat transfer. It was also reported that at evaporator with vaporization, nanoparticle remain at the evaporator surface which leads to rapid increase in nanofluid concentration at evaporator and eventually lead to premature dry out. Experiment ${ }^{3}$ were conducted and it was found that the optimal thermal efficiency occurred when the charge amount was $60 \%$, also the added nanoparticles at the concentration of $1.0 \mathrm{wt}$. \%,

*Author for correspondence 
showed the optimum value of thermal efficiency can be enhanced by $16.8 \%$ when compared with base fluid.

The ${ }^{4}$ effect of different operating parameters such as applied heat flux to the evaporator section, fill charge ratio of working fluid and volume concentration of nanoparticle on the thermal performance and efficiency of the thermosyphon heat pipe were studied experimentally At 5 vol. \%, the best fill charge ratio is $50 \%$ and $70 \%$ for alumina-water/EG (ethyleneglycol) and alumina-water/DEG (diethyleneglycol) nanofluids respectively. Performance ${ }^{-5}$ was investigated with five different nanofluids. Thermal conductivity was found to increase with particle concentration. Hence evaporator temperature gets reduced. Author reports the formation of coating layer on wire mesh which improved capillary structure and surface wettability. It also reduces contact angle and increases the surface roughness. Mesh heat pipe with best performance was $\mathrm{Al}_{2} \mathrm{O}_{3}$-water nanofluid with $5 \%$ volume concentration.

An experimental study ${ }^{\underline{6}}$ discussed about the thermal efficiency enhancement of the heat pipe based on the ratio of cooling capacity rate of condenser fluid at the condenser section and the supplied power at the evaporator section regarding $\mathrm{Cu} / \mathrm{DI}$ (De-Ionized)-water nanofluid as the working fluid. Experimental procedure was repeated for different heat inputs and different inclinations. The conclusions drawn from this study are the thermal efficiency of the heat pipe enhances about $10 \%$ when copper nanofluid is used as the working fluid. The heat pipe thermal efficiency increases with increase in inclination of the heat pipe up to $30^{\circ}$ for De-Ionized DI (DI) water and $45^{\circ}$ for copper nanofluid.

Experimental ${ }^{7}$ study was undertaken to investigate the thermal performance of an inclined miniature grooved heat pipe using water-based $\mathrm{CuO}$ nanofluid. They reported that the inclination angle has a strong effect on the heat transfer performance of heat pipes using both water and the nanofluid. The best result achieved at the inclination angle of $45^{\circ}$. In heat pipe using nanofluid, the maximum heat flux for inclined heat pipe can increase doubly and the inclination angle itself has only weak effects on the maximum heat flux.

Experimentally ${ }^{-}$investigated the effects of using silver water nanofluid on the heat transfer performance of a heat pipe and showed a substantial reduction in thermal resistance of $76.2 \%$ and an enhancement in the evaporation heat transfer coefficient of $52.7 \%$ for $0.009 \%$ silver nanofluid. Their results demonstrated that the use of nanoparticles enhances the operating range of heat pipe by $21 \%$ compared with that of DI water. Author ${ }^{9}$ have studied the impact of nanoparticles deposition on the vacuumed copper heat pipe wick porosity after several use of nanofluid as a working medium. They reported that at the beginning, the heat pipe performance showed a significant enhancement for using the nanofluids over the pure water, but this enhancement is later depreciated after several use. Thermal performance ${ }^{10}$ has been analyzed of inclined miniature mesh heat pipe using water based $\mathrm{CuO}$ nanofluid at different operating conditions. Their results show that the inclination angle has a strong effect on the heat transfer performance of heat pipes using both water and the nanofluid and at the inclination angle of $45^{\circ}$ best thermal performance for heat pipes is obtained using both water and the nanofluid. Study 11 shows the effect of filling ratio on thermal characteristics of circular heat pipe using nanofluid and water. The $\mathrm{CuO} /$ water nanofluid is used as the working fluid of experimental heat pipes with concentration of $1.0 \mathrm{wt}$. \%. This study focuses on the effects of heat input, fill ratio and angle of inclination on the thermal efficiency and thermal resistance of heat pipe. The results indicated that the thermal efficiency increases when nanoparticles are added with DI-water and also the thermal resistance of the nanofluid heat pipe decreases compared with that of the heat pipe using base fluid alone. The experimental ${ }^{12}$ analysis of cylindrical heat pipe was performed using copper nanofluid with an aqueous solution of $\mathrm{n}$-Hexanol. The experiment is carried out for various heat inputs and inclination angle of heat pipe. From experimental results, it is found that the thermal efficiency of copper nanofluid with an aqueous solution of n-Hexanol is higher than the base fluid DI water and copper nanofluid and thermal resistance also reduces to three fourth of base fluid. This study established ${ }^{13}$ that tilt angle and wick structure plays an extremely important role in the overall performance of the heat pipe. The transfer of heat from evaporator section to condenser section is reduced when the working fluid used has negative surface tension gradient. The author studied the behavior of heat pipe operated on aqueous solutions of $\mathrm{n}$-Pentanol at various orientations. The results drawn out from this study showed superior performance of the heat pipe when working on $n$-Pentanol fluid for the reason that the aqueous solutions have a positive surface tension gradient with temperature. 
In addition, the optimal inclination and optimal fill ratio of a heat pipe was reported as $45^{\circ}$ and $50 \%$, respectively ${ }^{14}$.

Based on the literature review, it is concluded that the suspension of nanoparticles in base fluid improves the thermal performance of heat pipes. The present experimental investigation has been carried out to determine the effects of heating power, inclination angle of heat pipe and concentration of nanofluid on the thermal performance of sintered wick heat pipe and mesh wick heat pipe.

\section{Experimental Setup and Procedure}

\subsection{Preparation of Nanofluid}

In the present study, water based $\mathrm{Al}_{2} \mathrm{O}_{3}$ nanofluid was used as the working fluid. $\mathrm{Al}_{2} \mathrm{O}_{3}$ nanoparticles were commercial products manufactured by Sigma Aldrich (Germany).

In the present work, DI water based $\mathrm{Al}_{2} \mathrm{O}_{3}$ nanofluids are prepared using two step method. The particles are spherical in shape and the maximum size is within $50 \mathrm{~nm}$. The nanofluid was prepared by directly dispersing $\mathrm{Al}_{2} \mathrm{O}_{3}$ nanoparticles into the deionized water with certain weight fraction. No surfactant was added into the base liquid. The prepared solution is kept in an ultra-sonicator for duration of 6 hours. The solution is dispersed uniformly and it obtains good stability. The nanofluid is prepared with three different concentrations, $0.5,1.0$ and $3.0 \mathrm{wt}$. \%. To consider the influence of nanoparticle concentration, the concentrations by volume fraction of nanoparticle were calculated using following equation ${ }^{5}$ :

$$
\% \text { volume fraction }=\frac{\frac{\omega_{n p}}{\rho_{n p}}}{\frac{\omega_{n p}}{\rho_{n p}}+\frac{\omega_{b f}}{\rho_{b f}}}
$$

Where, $\omega_{\mathrm{np}}, \rho_{\mathrm{np}}, \omega_{\mathrm{bf}}$ and $\rho_{\mathrm{bf}}$ are weight of nanoparticles, density of nanoparticles, weight of base fluid and density of base fluid respectively.

Further, a sedimentation test has also been conducted by keeping the prepared nanofluid statically for 30 days illustrated in Figure 1(a,b). The prepared sample is kept for 30 days and no separation line was found between the nanoparticles and water.
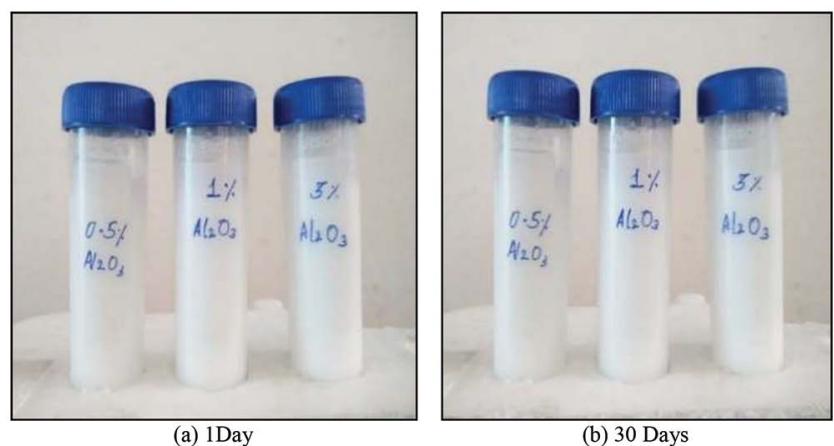

Figure 1(a,b). Sedimentation test for 0.5, 1.0 and 3.0wt. \% of $\mathrm{Al}_{2} \mathrm{O}_{3}$ nanofluid.

\subsection{Experimental Apparatus}

The heat pipe used in this study has a length of $600 \mathrm{~mm}$, an outer diameter of $12.7 \mathrm{~mm}$ and a thickness of $1.5 \mathrm{~mm}$ with copper as the pipe material. In all eight heat pipes are used in this work, four heat pipes are made with sintered wicks and the remaining four with mesh wicks. In both the cases, one heat pipe is filled with DI water and the other three with $\mathrm{Al}_{2} \mathrm{O}_{3}$ nanofluids. The wick thicknesses of both the heat pipes are maintained at a constant value of $1 \mathrm{~mm}$. The screen mesh wicks of two layers are scrolled into cylindrical shape and tightly affixed with the inner surface of heat pipe. The stainlesssteel wick with 150 mesh size is used as wick structure.

The sintered wick structure was made from pure red copper powder having particle size ranging between 150 and $250 \mu \mathrm{m}$ grades. A mandrel with an end cap was inserted in the copper pipe in order to leave a central vapor channel open. The powder was then placed in the annulus between the mandrel and the pipe and compacted to eliminate any gross cavities in the wick. The pipe, the powder and the mandrel were then heated in an electric furnace at $850^{\circ} \mathrm{C}$ for 30 minutes. Then,
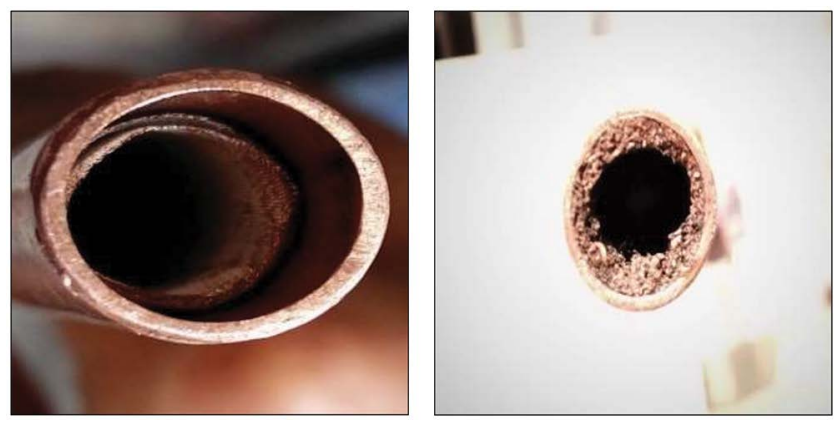

Figure 2. Cross-sectional view of sintered and mesh wick heat pipes. 
the pipe was cooled and the mandrel was removed. Figure 2 represents the detailed cross-sectional view of both sintered and mesh wick heat pipes.

Seven K-type thermocouples are attached over the surface of heat pipe, two at the evaporator section, two at the adiabatic section and the remaining three at the condenser section. The condenser section is cooled by liquid water to extract more amount of heat from the heat pipe compared with air cooling. The evaporator and adiabatic sections are perfectly insulated with glass wool to minimize the heat losses between the heat pipe and the surroundings.

Experiments are conducted with MWHP and SWHP using DI water and three different concentrations viz. $0.5,1.0$ and 3.0 wt. $\%$ of $\mathrm{Al}_{2} \mathrm{O}_{3}$-DI water nanofluids. The schematic layout of the experimental setup is as shown in Figure 3. The setup consists of a pump and a flow meter to circulate cooling water at a constant flow rate through the condenser section. The temperatures of the cooling water circulating through the condenser section are recorded by using two K-type thermocouples fixed at inlet and outlet of the condenser. Approximately 30 minutes duration is maintained between each heat input increment. The heat input starts from $20 \mathrm{~W}$ with an increment of $20 \mathrm{~W}$ till the heat pipe reaches dry out. The heat pipe inclination angle is varied using a variable angle holder from its horizontal axis to 30 , 45,60 and $90^{\circ}$.

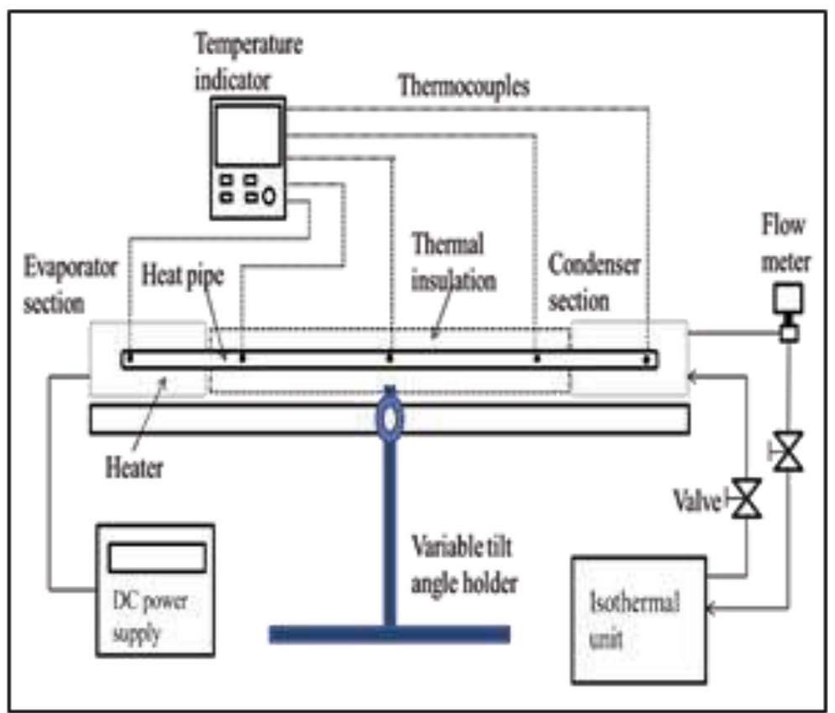

Figure 3. Schematic diagram of experimental apparatus.

\section{Results and discussion}

Experiments are conducted with sintered wick and mesh wick heat pipes. Steady state conditions are maintained throughout the study. For both the cases, heat input (20, $40,60,80$ and $100 \mathrm{~W}$ ), concentration of working fluid (0.5, 1.0 and $3.0 \mathrm{wt} . \%$ of $\mathrm{Al}_{2} \mathrm{O}_{3} / \mathrm{DI}$ water nanofluids) and tilt angle $\left(0,30,45,60\right.$ and $\left.90^{\circ}\right)$ are varied and the effect of these parameters on the thermal resistance and thermal efficiency is evaluated and analyzed.

\subsection{Thermal Resistance of Heat Pipes}

Thermal resistance of a heat pipe is defined as the ratio of surface temperature difference between the evaporator and condenser sections and the heat input, where $\mathrm{Q}=\mathrm{V} \times \mathrm{I}$. It is given by,

$$
R=\frac{T_{e}-T_{c}}{Q}
$$

with $\mathrm{T}_{e}$ as the average wall temperature of the evaporator section, $T_{c}$ as the average wall temperature of the condenser section and $\mathrm{Q}$ as the input power.

Figure 4(a-e) and 5(a-e) represents the thermal resistance vs. heat input of MWHP and SWHP with DI water, varying mass concentrations of $\mathrm{Al}_{2} \mathrm{O}_{3}$ nanofluid and inclination angles. The value of thermal resistance is higher at lower loads than the higher heat loads. This happens due to the formation of liquid layer in the evaporator section at low heat inputs and this layer disappears when the heat input is increased. All the figures show a rapid reduction in thermal resistance with heat input.

The thermal resistance of heat pipe decreases with increasing nanofluid concentration and tilt angle for both type of heat pipes. At low heat input the thermal resistance of heat pipe is high because of the relatively solid liquid film that resides in the evaporator section. When the heat pipe orientation and concentration of nanofluid increases, these thermal resistances condense quickly to their minimum value.

The thermal resistance decreases with the increasing concentration of $\mathrm{Al}_{2} \mathrm{O}_{3}$ nanoparticles till 1.0 wt.\% and increases beyond this level. This happens due to the formation of a thin porous layer on the mesh and sintered wick, which increases the surface wettability by reducing solid-liquid contact angle. At high heat loads, the formation of solid-liquid layer in the evaporation 


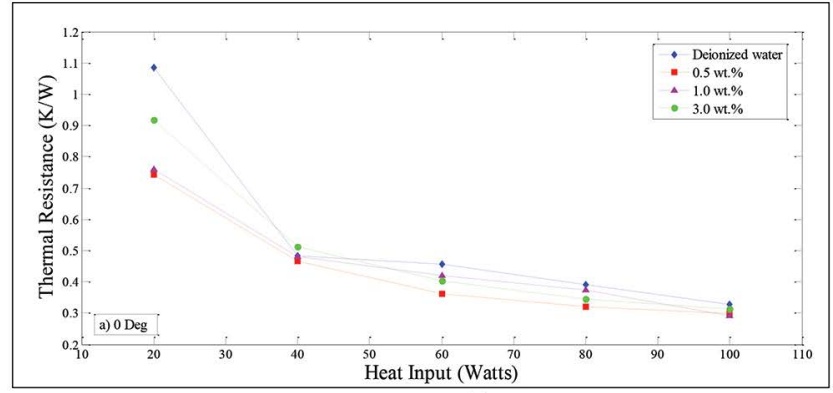

(a)

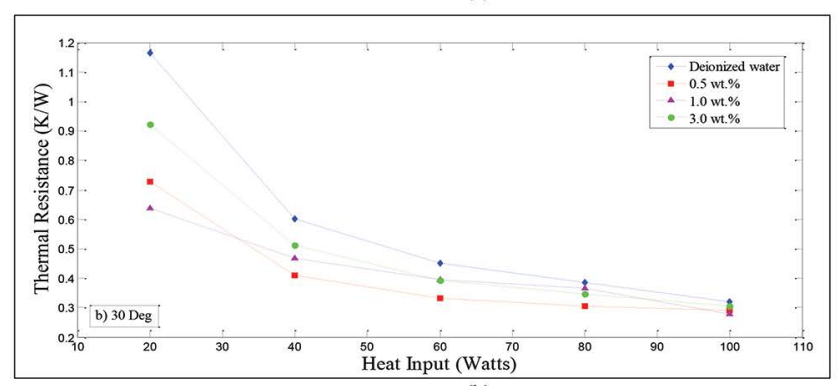

(b)

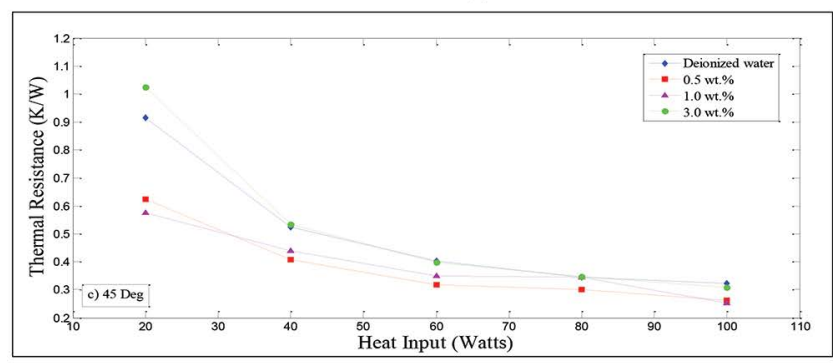

(c)

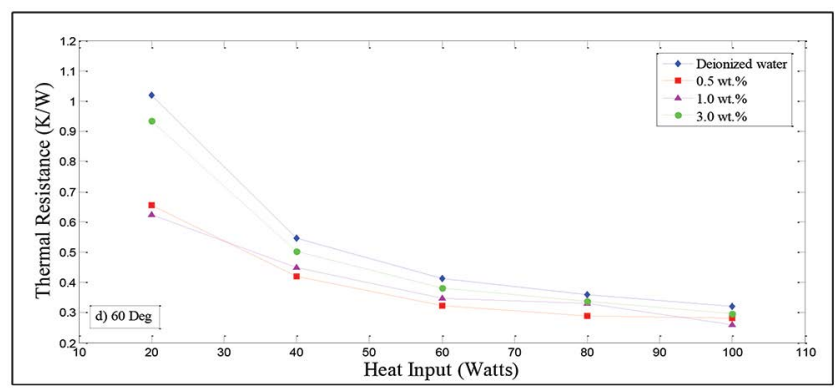

(d)

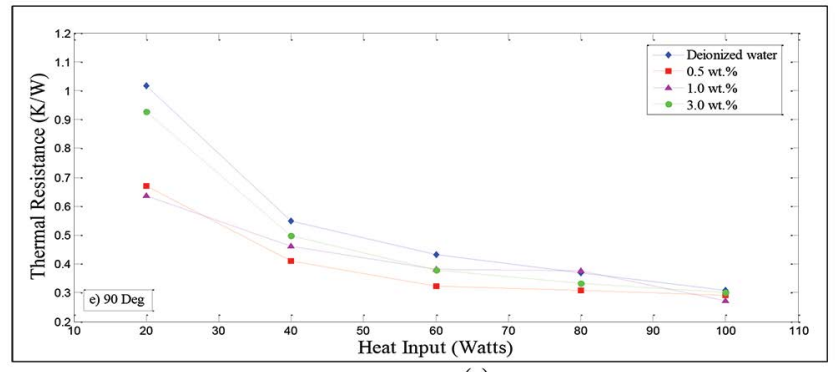

(e)

Figure 4(a-e). Thermal resistance variation of MWHP for different concentration of $\mathrm{Al}_{2} \mathrm{O}_{3}$ nanofluid and inclination angles.

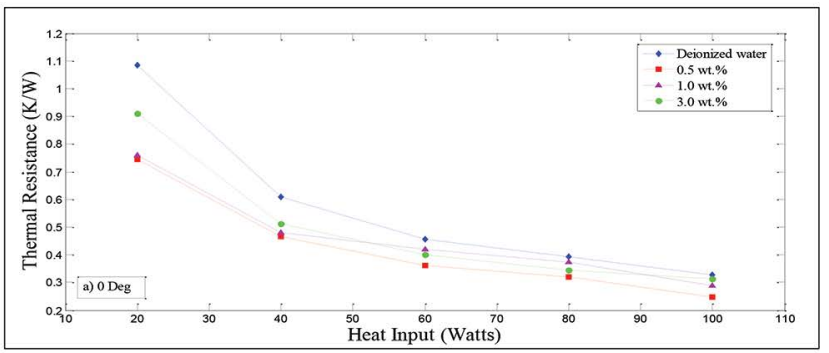

(a)

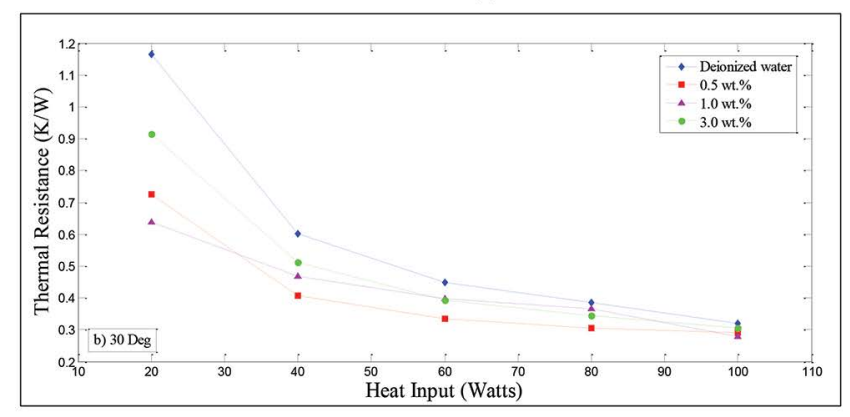

(b)

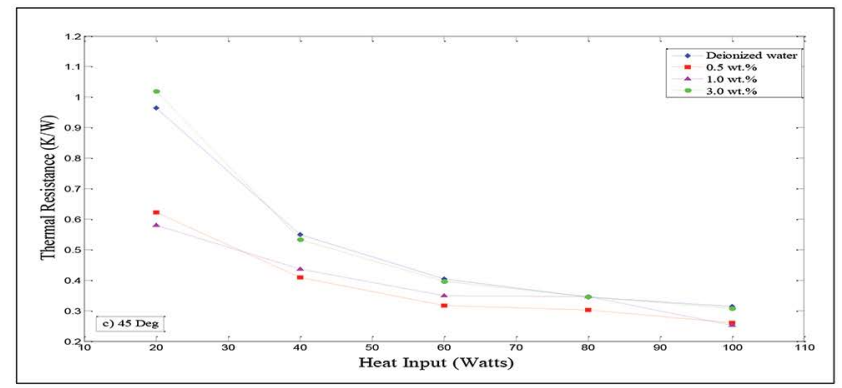

(c)

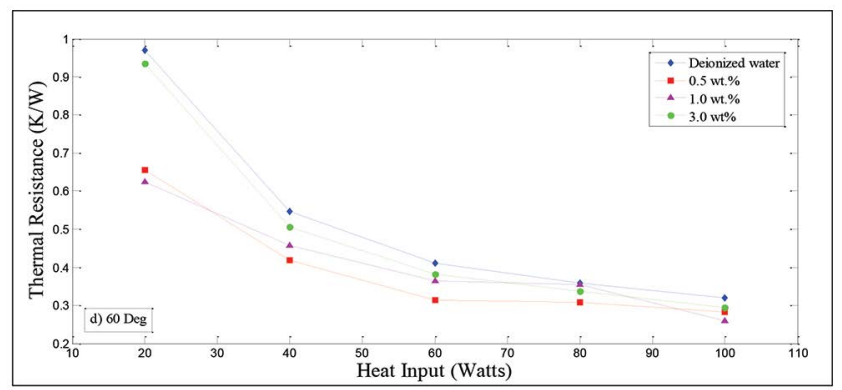

(d)

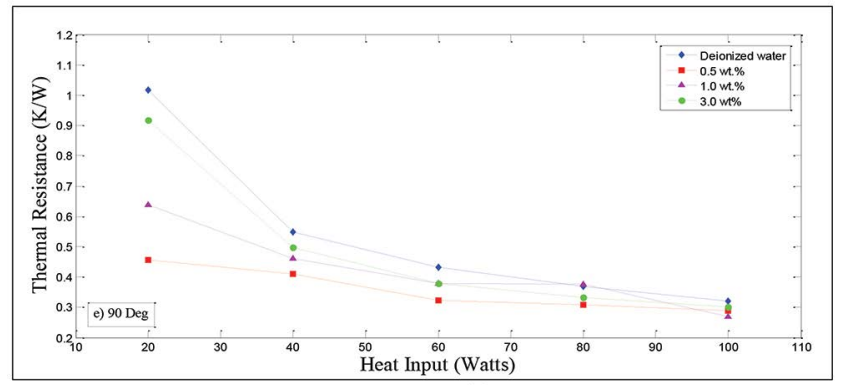

(e)

Figure 5(a-e). Thermal resistance variation of SWHP for different concentration of $\mathrm{Al}_{2} \mathrm{O}_{3}$ nanofluid and inclination angles. 
section is reduced. Thus, the thermal resistance steadily decreases with increasing nanoparticles concentration and heat load.

Maximum reductions in thermal resistance in MWHP is observed at $45^{\circ}$ tilt angle for $1.0 \mathrm{wt}$. $\%$ of $\mathrm{Al}_{2} \mathrm{O}_{3}$ nanofluid is $21.92 \%$, whereas for SWHP the value is $24.36 \%$ at $60^{\circ}$ tilt angle. Another interesting observation is that the use of sintered wick reduces the surface temperature and thermal resistance and improves the heat transport capacity compared with mesh wick.

In both the heat pipes, the optimum weight fraction of nanofluid is found to be $1.0 \mathrm{wt}$. \%. Inclination angle of heat pipes has a significant effect on the thermal resistance.

Compared with the horizontal position, a remarkable reduction in thermal resistance is observed with increasing tilt angle. It is gradually reduced and a maximum reduction is obtained at $45^{\circ}$ for MWHP and $60^{\circ}$ for SWHP.

\subsection{Effect of Inclination Angle on Thermal Efficiency}

The thermal efficiency of the heat pipe is calculated by the ratio of cooling capacity rate of condenser fluid at the condenser section and the supplied power at the evaporator section. Figure $6(\mathrm{a}, \mathrm{b})$ shows the variations of heat pipe thermal efficiency for deionized water and

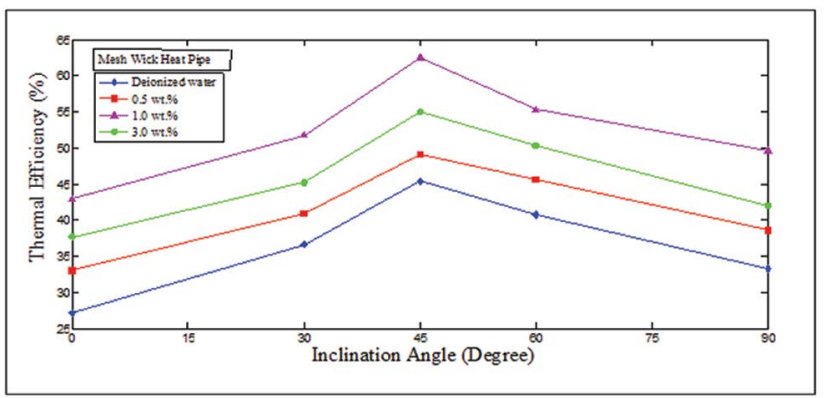

(a)

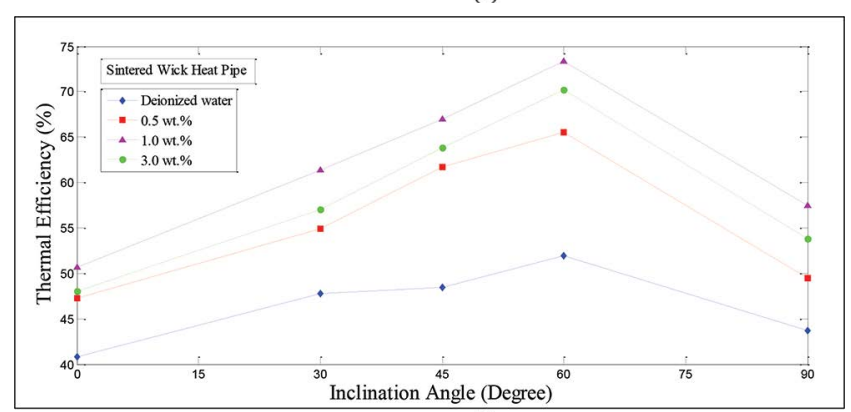

(b)

Figure 6(a,b). Variations of thermal efficiency of MWHP and SWHP for different inclination angle.
0.5, 1.0 and 3.0 wt. $\%$ of $\mathrm{Al}_{2} \mathrm{O}_{3}$ nanofluids for various tilt angles for mesh wick heat pipe and sintered wick heat pipe respectively.

From the graphs, it has been observed that the efficiency of heat pipe increases with increasing values of the tilt angle. This is due to the fact that the gravitational force has a significant effect on the flow of working fluid between the evaporator section and the condenser section along with the capillary action of wick.

However, when the heat pipe inclination angle exceeds $45^{\circ}$ for mesh wick heat pipe and $60^{\circ}$ for sintered wick heat pipe the heat pipe thermal efficiency tends to decrease. The efficiency of the heat pipe seems to decrease since the formation of the liquid film is at higher rate inside the condenser which results in the increased value of the thermal resistance between the vapor of the working fluid and the cooling medium in the condenser. Therefore, the thermal efficiency decreases when the angle exceeds $45^{\circ}$ for mesh wick heat pipe and $60^{\circ}$ for sintered wick heat pipe for $\mathrm{Al}_{2} \mathrm{O}_{3}$ nanofluids.

In this analysis, the thermal efficiency of heat pipe increases by about $37.55 \%$ for $1 \%$ conc. of $\mathrm{Al}_{2} \mathrm{O}_{3}$ nanofluid as a working fluid when compared with the deionized water in mesh wick heat pipe at an inclination of $45^{\circ}$. Besides, the sintered wick heat pipe which uses $1.0 \mathrm{wt}$. $\%$ conc. of $\mathrm{Al}_{2} \mathrm{O}_{3}$ nanofluid as working fluid the thermal efficiency increases to nearly about $41.38 \%$ as compared to that of deionized water at an inclination of $60^{\circ}$.

Generally, the nanoparticles suspension in the fluid has significant effect on the enhancement of heat transfer due to its higher heat capacity and higher thermal conductivity of working fluid. Therefore, the thermal efficiency of heat pipe increases with nanofluids as compared to that of the base working fluid.

\section{Conclusions}

Thermal performance analysis of mesh wick and sintered wick heat pipes are experimentally studied using $\mathrm{Al}_{2} \mathrm{O}_{3} /$ DI nanofluids at various heat input and inclination angles and the following conclusions are made:

- The thermal efficiency of heat pipe using $\mathrm{Al}_{2} \mathrm{O}_{3}$ nanofluid is higher than the base fluids like deionized water and the thermal resistance is also considerably less than the deionized water.

- The inclination angle and weight percentage of $\mathrm{Al}_{2} \mathrm{O}_{3}$ nanoparticles significantly influence 
the thermal performance of both sintered wick heat pipe and mesh wick heat pipe. The thermal resistance of heat pipe decreases with increasing nanofluid concentration and tilt angle for sintered wick and mesh wick type of heat pipes. Thermal resistance of heat pipe decreases with increase in heat input whereas the thermal conductivity of the heat pipe increases with heat flux.

- Optimum tilt angles of $45^{\circ}$ and $60^{\circ}$ respectively are observed for mesh wick and sintered wick heat pipes, whereas the optimum weight percentage is the same (1 wt. \%) for sintered wick and mesh wick heat pipes.

- At tilt angle of $45^{\circ}$ and 1.0 wt. \% concentration of $\mathrm{Al}_{2} \mathrm{O}_{3}$ nanofluid, for mesh wick heat pipe a reduction in thermal resistance of $21.92 \%$ and an enhancement in the thermal conductivity of $19.83 \%$ are observed respectively, when compared with heat pipe using DI water alone.

- Similarly, at tilt angle of $60^{\circ}$ and $1.0 \mathrm{wt}$ \% concentration of $\mathrm{Al}_{2} \mathrm{O}_{3}$ nanofluid, for sintered wick heat pipe a reduction in thermal resistance of $24.36 \%$ and an enhancement in the thermal conductivity of $21.85 \%$ are observed respectively, when compared with heat pipe using DI water alone.

- The enhancement in thermal efficiency of mesh wick heat pipe is about $37.55 \%$ for $1.0 \mathrm{wt}$. \% concentration of $\mathrm{Al}_{2} \mathrm{O}_{3}$ nanofluid as a working fluid when compared with the deionized water at an inclination of $45^{\circ}$. Besides, the heat pipe which uses $1.0 \mathrm{wt}$. \% concentration of $\mathrm{Al}_{2} \mathrm{O}_{3}$ nanofluid in sintered wick heat pipe enhances the thermal efficiency to nearly about $41.38 \%$ as compared to that of deionized water at an inclination of $60^{\circ}$.

Nomenclature
\begin{tabular}{|l|l|l|}
\hline$Q$ & $:$ Heat supplied (Watts) \\
\hline$I$ & $:$ Current $(\mathrm{A})$ \\
\hline$V$ & $:$ Voltage $(\mathrm{V})$ \\
\hline$R$ & $:$ Thermal resistance $(\mathrm{K} / \mathrm{W})$ \\
\hline$T_{c}$ & $:$ Average condenser surface temperature $\left({ }^{\circ} \mathrm{C}\right)$ \\
\hline$T_{e}$ & $:$ Average evaporator surface temperature $\left({ }^{\circ} \mathrm{C}\right)$ \\
\hline & $\omega_{n p}$ & $:$ Weight of nanoparticles \\
\hline & $\rho_{n p}$ & $:$ Density of nanoparticles \\
\hline & $\omega_{b f}$ & $:$ Weight of base fluid \\
\hline & $\rho_{b f}$ & $:$ Density of base fluid \\
\hline & & DI $:$ Deionized \\
\hline
\end{tabular}

- Increase in thermal efficiency of heat pipes is due to the fact that gravity has a significant effect on the flow of working fluid between the evaporator section and the condenser section along with the capillary action of wick.

\section{References}

1. Nookaraju Ch. B, et al. Thermal analysis of gravity effected sintered wick heat pipe, Materials Today: Proceedings. 2015; 2:2179-87. https://doi.org/10.1016/j. matpr.2015.07.230.

2. Hung $\mathrm{Y}-\mathrm{H}$, et al. Evaluation of the thermal performance of a heat pipe using alumina nanofluids, Experimental Thermal and Fluid Science. 2013; 44:504-11. https://doi. org/10.1016/j.expthermflusci.2012.08.012.

3. Teng $\mathrm{T}-\mathrm{P}$, et al. Thermal efficiency of heat pipe with alumina nanofluid, Journal of Alloys and Compounds. 2010; 504S:S380-84. https://doi.org/10.1016/j.jallcom.2010.02.046.

4. Sarafraz MM, et al., Experimental study on the thermal performance and efficiency of a copper made thermosyphon heat pipe charged with alumina-glycol based nanofluids, Powder Technology. 2014; 266:37887. https://doi.org/10.1016/j.powtec.2014.06.053.

5. Putra N, et al., Thermal performance of screen mesh wick heat pipes with nanofluids, Experimental Thermal and Fluid Science. 2012; 40:10-17. https://doi. org/10.1016/j.expthermflusci.2012.01.007.

6. Senthilkumar R, Vaidyanathan S, Sivaraman B. Effect of inclination angle in heat pipe performance using copper nanofluid. Procedia Engineering. 2012; 38:3715-21. https://doi.org/10.1016/j.proeng.2012.06.427.

7. Liu $\mathrm{Z}-\mathrm{H}$, et al. Thermal performance of inclined grooved heat pipes using nanofluids, International Journal of Thermal Sciences. 2010; 49:1680-87. https://doi. org/10.1016/j.ijthermalsci.2010.03.006.

8. Asirvatham LG, et al. Heat transfer performance of screen mesh wick heat pipes using silver-water nanofluid, International Journal of Heat and Mass Transfer. 2013; 60:201-09. https://doi.org/10.1016/j. ijheatmasstransfer.2012.11.037.

9. Mohamed I. Hassan, et al., The effect of water-based nanofluid incorporating $\mathrm{Al} 2 \mathrm{O} 3$ nanoparticles on heat pipe performance, Energy Procedia. 2015; 75:3201-06. https:// doi.org/10.1016/j.egypro.2015.07.674. 
10. Wang $\mathrm{P}-\mathrm{Y}$, et al. Application of nanofluid in an inclined mesh wicked heat pipes, Thermochimica Acta. 2012; 539:100-08. https://doi.org/10.1016/j.tca.2012.04.011.

11. Manimaran $\mathrm{R}$, et al. Effect of filling ratio on thermal characteristics of wire -mesh heat pipe using copper oxide nanofluid, Frontiers in Heat Pipes (FHP). 2012; 3(02):3004. https://doi.org/10.5098/fhp.v3.2.3004.

12. Senthilkumar R, Vaidyanathan S, Sivaraman B. Experimental analysis of cylindrical heat pipe using copper nanofluid with an aqueous solution of
n-Hexanol, Frontiers in Heat Pipes (FHP). 2012; 2(3). https://doi.org/10.5098/fhp.v2.3.3004.

13. Senthilkumar R, Vaidyanathan S, Sivaraman B. Performance investigation of heat pipe using aqueous solution of $\mathrm{n}$-Pentanol with different inclinations, Journal of Mechanical Science and Technology. 2011; 25(4):923. https://doi.org/10.1007/s12206-011-0207-4.

14. Chandrasekaran SK, Srinivasan K. Experimental studies on heat transfer characteristics of ss304 screen mesh wick heat pipe. Thermal Science. 2017 Jan 1;21(2):S497-502. 